\title{
Strategic Management and Supply Chain Management in Organizational Theory Perspective: A Synergistic Approach
}

\author{
Hafiz Muhammad Naeem \\ National College of Business Administration \& Economics \\ East Canal Campus, Lahore \\ Nazia Munazer Hussain \\ Global Institute, Lahore
}

\begin{abstract}
An ultimate question mark in history of strategic management is why and how organizations perform better than others? One comparative answer to explain this phenomena is an organization's actions and strategic choices how it operate its supply chain. Supply chain management with the strategic management viewpoint is very fertile area and its integration can enrich this domain significantly. Network competition, hypercompetition and new competitive landscape got paramount significance in today's competitive environment and strategy building process. The basic purpose of this literature review is to explain this shortcoming while explaining intended outcomes extracted from crucial abilities and configuration of supply chain management principles in hypercompetitive industries. While taking network competition, this report also extends the reference point of Abdulla (2009) on strategic demand network management (SDNM). Moreover this conceptual review will also develop a linkage in academic literature with respect to dynamic capabilities and supply chain management.
\end{abstract}

Keywords: Supply Chain Management, Strategic Demand Network Management, Strategic Management, Dynamic Capabilities, Literature Review

\section{INTRODUCTION}

From last couple of decades, many organizations are expanding their business internationally due to maturity and saturation in domestic markets. To expend globally, organizations are required some noteworthy strengths like supply chain management capabilities, process innovation, product innovation, marketing expertise, human resource and competitive brands. This sudden shift in business environment forced the organization to put more emphasized on supply chain management for overall competitive advantage. Well competing organizations developed their supply chain management as their key competitive advantage because of changing geopolitical events (market access to Brazil, Russia, India, China, North America Free Trade Agreement and European Union) deregulations of national policies and global expansion thus increased pressure on competitors (Fawcett et al., 2014; Christopher, 2012). Apart from corporate/strategic importance of supply chain management, academic literature also supports the notion of collaborative and integrative approach of supply chain and competitive advantage on theoretical as well as empirical basis. But, organizations manage their businesses in hypercompetitive conditions may face arduous challenges while integration and collaboration of supply chain with dynamic capabilities due to constraints in strategic flexibility. But on theoretical basis, the integration of dynamic capabilities and supply chain management is relatively new concept in dynamically changing industries (Beske, Land, and 
Seuring, 2014). In presence of these constraints, organizations may emasculate their abilities in creating series of temporary advantages in discontinuous changing, relentless and rapid business environments.

Carter and Roger (2008) contended that sustainable advantage, across a breadth of industries, replaced by temporary advantage dramatically. Key aspects like flexible manufacturing, communication, technology revolutions and globalization have changed the nature of competition on entry barriers, product life cycles, radical innovation, market speed, quality and price (D'Aveni, 1994). All of these factors are unpredictable, discontinuous, evolutionary and competence-enhancing in nature. Apart from above said factors, changing nature in playing field, devalued products, fluid participants, uncertain relationships and disruptive technologies also converted the business environment into unpredictable and turbulent for creating value added supply chain functionally and strategically. Many researchers (for reference Min, Mentzer, \& Ladd, 2007; Min et al., 2005; Chen, Daugherty, \& Landry, 2009; Dyer \& Singh, 1998) argued that competitive forces seems to be discordant with mainstream models that supports building mechanism, reward and risk sharing, process integration, demand and supply data, processes, information, knowledge sharing, idiosyncratic investments, trust and long term partnerships. Gersick (1991) suggested these events as “... merely signal a punctuated equilibrium cycle, but it is equally likely that relentless competitive disruption will continue, and create an enduring and more hostile competitive environment in which firms at best achieve a series of temporary advantages". If an organization faced above said facets then we called it hypercompetition as defined by D'Aveni's (1994). The academic literature is sparse on developing linkage between hypercompetitive mindset and supply chain management.

\section{LITERATURE REVIEW}

With respect to prior literature, supply chain management defined as "the configuration of managerial and strategic choices a firm makes regarding the intended interactions, relationships, expected benefits and outcomes resulting from relations with members of its supply chain(s)" (Wisner et al., 2015; Hugos, 2011; Lee, Miranda \& Kim, 2004; Xie et al., 2011; Christopher \& Towill, 2002). In today's competitive environment, the paradigm of supply chain management from efficient transformation of information, money and material is changed to effective sharing in networks/value chain and improving performances. That is why we are seeing numerous calls for research studies that integrate supply chain management with organizational and strategy research (Miles and Snow, 2007; Christopher et al., 2006; Ketchen, Hult and Slater, 2007; Bettis, Helfat, and Shaver, 2013; Hoffmann, Lavie, Reuer and Shipilov, 2014). Without any doubt, the inclusion of strategic research in supply chain management is beneficial for organizations in terms of enabling, developing and implementing organizational strategies. Despite the seminal work of Porter (1985), indicated the conception of value chain with integration of strategic behavior, relationships and processes of supply chain management with strategic behavior is still disintegrated. Therefore, dynamic capabilities, knowledge-based view, resource based view, strategic choice, social capital theory, network theory, game theory, institutional theory, resource dependence theory, institutional theory, agency theory and transaction cost economics theory come into play for supply chain management literature (for example: Peteraf et al., 2013; Teece, 2007; Helfat and Winter, 2011; Barney and Felin, 2013; Camuffo, Furlan and Rettore, 2007; Ketchen \& Giunipero, 2004; Saeed et al., 2011; Cheng \& Grimm, 2006).

On the foundation some recent arguments (Pacheco-de-Almeida, 2010; D'Aveni, Dagnino, \& Smith, 2010) and call for papers, this literature review is devised on this question. How organization should manage its supply chain based on different environmental situation 
requires unpredictability, self-cannibalization, aggressiveness, secrecy, stealth and speed to achieve competitive advantage? After answering this question with the help of available theories, three key developments/significance/contribution/motivations also discussed subsequently. The first development is related with the integration of dynamic capabilities framework of strategic management with supply chain management research. More specifically, it will explore how supply chain management concept and practices instigate organizations to obtaining and achieving dynamic capabilities. Captivatingly, researchers (Zahra, Sapienza, \& Davidsson, 2006; Eisenhardt \& Martin, 2000) proposed that dynamic capabilities is not enough to get competitive advantage. Accordingly, this work will try to answer how supply chain management practices are significant for obtaining dynamic capabilities while taking network based competition into consideration. Moreover, this literature review will also explain the role of dynamic capabilities in supply chain designs and supply chain practices.

The second development of this work is to amalgamate supply chain management with alliance research, network theory and relational view with respect to strategic management. Since the basic purpose of supply chain practices is to interact between independent yet interdependent network of firms and interactions of employees working in it, this is why network theory and relational view can add food for thought in academic literature. Since supply chain management field is in developing phase in accordance to network theory and relational view so adding these concepts in this field will help researchers' and practitioners' understanding about designing and implementing effective supply chain practices. To enhance performance, organizations used Triple A of supply chain (Lee, 2004; Ishaq et al., 2011) - alignment (synergistic interest), adaptability (managing few chains within available resources) and agility (ability to be responsive and proactive) - in order to give competitive priorities and flexibility. The third development of this literature review is built on knowledge-based view and resource based view which represents supply chain as catalyst of effective boundary decision making and strategic entrepreneurship.

\section{PRESENTATION OF STUDIES}

Rajaguru and Matanda (2013) published their research in Industrial Marketing Management on the title "Effects of inter-organizational compatibility on supply chain capabilities: Exploring the mediating role of inter-organizational information systems (IOIS) integration". The basic purpose of this research study was to investigate the impact of inter-organizational computability and supply chain capabilities and also examining the mediating role of interorganizational informational system (IOIS) in above said relationship. To support their basic research question, the authors used interdisciplinary theories like network theory and claimed that there is setback of these theories because of inability to explain the role of information systems integration with supply chain. So authors developed their arguments with the combination of dynamic capability theory, resource based theory and congruence theory to understand the conceptual relationships of supply chain capabilities, IOIS and interorganizational compatibility. From the conceptual framework, authors devised ten hypotheses and incorporate firm size as control variable.

The sample of this study was generated through Yellow Pages and Australian Centre for Retail Studies in hardware, liquor and supermarket retailing sectors. After sending questionnaire to 2000 randomly selected organizations, only 196 respondents returned the questionnaire with $15 \%$ response rate. Non-response bias, common method bias, multicollinearity, confirmatory factor analyses and structural equation modeling was used to test the hypotheses. The statistical analyses showed that firm size, cultural compatibility, strategic compatibility and technical compatibility had positive and significant impact on IOIS integration while IOIS 
integration also put positive influence on supply chain capabilities. Moreover, firm size and cultural compatibility were linked positively with supply chain capabilities while strategic compatibility and technical compatibility did not have significant impact on dependent variable. With respect to mediating mechanism, IOIS integration fully mediate the relationship of supply chain capabilities - technical compatibility, supply chain capabilities - strategic compatibility and partially mediate the relationship of supply chain capabilities and cultural compatibility.

With my point of reference, this study has some significant contributions for practicing managers, working in business-to-business organization, to develop supply chain capabilities with the help of IOIS integration. Managers should take into cultural, strategic and technical inter-organizational compatibility with IOIS integration to gain competitive advantage. Another implication for managers is to perilously analyze the suppliers on the basis of congruency and compatibility of attitudes, goals and values ahead of IOIS implementation. Third, organization should also take partnering organizations into consideration while integrating IOIS with supply chain strategies. In addition to it, this study also has several limitations that should take into consideration while taking future research on the same domain. This research is cross-sectional in nature which gives information at one time of reference so conduction longitudinal research would be more feasible to understand the time lags, investments on IOIS implementations and benefits realized after it. Another crucial limitation is the generalization of results into other industries as this study was conducted on retailer industry only. Moreover, I found one drawback of this study as well. The authors took firm size as control variable but taking industry type as control variable would have different results. The reason for this is that researchers collected the data from three different retailing industries i.e., liquor, supermarkets and hardware with different market share, point of sale, supply chain, target market etc.

Fraj, Martinez and Matute (2013) conducted research on "Green Marketing in B2B Organizations: An Empirical Analysis from the Natural Resource Based View of the Firm" published in Journal of Business and Industrial Marketing. The basic purpose of this research was to understand the influential role of green marketing strategies in B2B organizational performance in accordance to natural resource based view (NRBV). This study was conducted on under-researched topic i.e. natural resource based view and test theoretical underpinnings empirically and proposed noteworthy implications of green marketing strategies with its competitive consequences. Indubitably, greening environment took paramount importance from practitioners and researchers perspectives and most salient journals published special issues on greening/environmental issues. Despite the availability of academic literature that developed the linkage between proactive strategies and performance (Menguc and Ozanne, 2005; Christmann, 2000, 2004) with different variables (Lopez et al., 2009) proposed fragmented results but many questions are still ambiguous, tricky, unclear and unanswered. Consequently, practitioners are academicians are still looking for non-unanimous answers of normative questions like: do green strategies beneficial for organization (Delmas et al., 2011; Hillman and Keim, 2001)? To understand the role of green marketing practices in supply chain, its consequences, organizational capabilities and resources required in implementing these strategies in industrial firms, researchers used natural resource based view (NRBV) proposed by Hart (1995).

To answer their research questions, data was collected from 2098 industrial firms from European country. The organization selection was did on the basis of minimum 150 employees, size of the firm, role in country's economy and environmental practices 
implementing. Most relevant industries within the population were automobiles, furniture, electronics, metallurgy, machinery, chemical, non-mineral, wood and paper, textiles and food. As explained previously, this study tried to test the green marketing strategies on performance and to what extent environmental culture, practices and intrinsic organizational resources supports green marketing strategies to enhance organizational performance. The results indicated that green marketing strategies had two unique dimensions in B2B context: market oriented activities and process oriented activities. Researchers defined market oriented activities as "undertaken with the purpose of projecting externally a greater environmental commitment" whereas process oriented activated referred as "environmental actions, including transformations of products and internal processes, that are aimed at reducing environmental impact". For second research questions, the results showed that companies with strong environmental culture always showed more enthusiasm in developing green marketing / environmental friendly marketing strategies. Based on the article, there are some recommendations for future researchers. In order to measure environmental practices along with their consequences, subjective measures were used which may reflect social desirability bias in results. Being a cross-sectional study in nature, researchers did not evaluate the dynamics in environmental decisions.

Allred, Fawcett, Wallin and Magnan (2011) published their article in Decision Science Journal with the title of "A Dynamic Collaboration Capability as a Source of Competitive Advantage". The authors supported the notion of resource based view of the firm that referred as how an organization develop non-substitutable, rare, inimitable and value capabilities in its supply chain to get superior performance and inimitable advantage. But they also argued that it required high level of coordination activities among all players which are, unfortunately, missing in many organizations. So inter-organizational conflicts and manifest cross functional teams obstruct the collaboration advantages. Despite having considerable researches in resource based view (RBV), there is still some dearth in the process that allows the organizations to invest supply chain and firm resources to attain distinctive capabilities (Barreto, 2010). More specifically, RBV has two extensions that explain the process of competitive differentiation. Firstly, researchers (Barney, 1992; Wernerfelt, 1984; Teece et al., 1997) focused on the resource heterogeneity aspect of RBV which emphasized on the resource configurations for distinctive performance. Second perspective explained by Dyer and Singh (1998) as "some of the resources needed to achieve distinctive advantage are often embedded in inter-firm resources and routines". That's why researchers (Ketchen et al., 2007; Fawcett et al., 2007) declared supply chain relationships as potential source of differentiations and vital complementary resources of competitive advantage. But coordinating actions among interorganizational and functional boundaries is somewhat arduous (Ellinger et al., 2006).

While giving background for hypotheses, the authors summarized the research question as "how decision makers use collaboration to enable their firms to combine and configure resources across organizational boundaries". To analyze their questions, the use multi-method technique of data collection - combination of survey and interviews - in two cross-sectional sets in two time periods based on 6 years. Several theories explicitly or implicitly discussed the impact, development and importance of collaboration in supply chains as dynamic capability. To understand the distinctiveness of collaboration advantage, researchers discussed three streams that derived from the literature: (1) inter-functional and supply chain collaboration, (2) conflict and organizational orientations, and (3) RBV of an organization. The total usable surveyes were 980 with $15.21 \%$ response rate. After the surveys, interviews were conducted in two different periods across four channel positions - service providers, direct material suppliers, finished goods assemblers and retailers. 51 interviews for period 1 and 58 interviews for period 2 were conducted from fifteen 15 organizations. After checked 
multicollineraity and non response bias, confirmatory factor analysis and structure equating modeling was used to test the hypotheses. The results concluded that “...relationship between a firm's customer orientation and its ability to create value as measured by satisfaction and productivity". The researchers also found positive impact of firm's supplier orientation on firm performance for both time laps.

While collecting the data through surveys and interviewing the respondents help the research to understand the in-depth analysis of supply chain collaboration which is not possible if researchers were conducted survey research, case study and single period data collection. Despite this powerful argument, this study still has some limitations. First of all the applicability of measuring instruments of dynamic capabilities and market orientation because the concepts were new and these measures are yet to be accepted on widely basis. In spite of limitation in case study research design, a small-scale case study that follows the same companies over time could provide additional details regarding the dynamics of developing a collaboration capability. This study was only used two aspects of market orientation, supplier and customer, so future researchers should also take governmental agencies, competitors and channel members into consideration.

\section{CONCLUDING REMARKS AND RECOMMENDATIONS}

In summary, this study found immediate and substantial market value implications for firms being publicly ranked for supply chain competence. Consequently, winning such recognition is strategic, not cosmetic in nature. The immediate and asymmetric benefit this award creates is good news for firms embracing integrative and collaborative supply chain management. However, it may be frustrating news for firms that find integrative and collaborative practices do not work well in the strategic context in which they operate. Strategic supply chain management research has yet to adequately address whether alternative configurations of strategic supply chain management practices can provide a better explanation of supply chain management contribution to firm performance under different competitive conditions. This study has hopefully encouraged reflection on and further research into: (1) the pressures firms face to adopt integrative and collaborative supply chain management, (2) the alternatives available to integrative and collaborative supply chain management, and (3) what supply chain management competence means. Oliver Williamson's (2008) challenged supply chain researchers to answer "What is the methodology for SCM?" and "What is the main case for SCM?" As this study shows, the answers to these questions hold market valuation consequences for firms.

This study sought to make two main contributions. First, this study aimed to add to the literature explaining firm performance. This study consequently adds to a body of evidence suggesting investors are considering factors related to supply chain management in their valuation of firms. Not only are investors considering news about supply chain disasters (e.g. Hendricks \& Singhal, 2003; 2009), excess inventory (Hendricks \& Singhal, 2008), supply chain management information systems (Filbeck et al., 2005) in their valuations, they also appear to consider rankings of overall supply chain management competence. The study also complements Ellinger and colleagues' research showing firms ranked in the Gartner Supply Chain Top 25 outperform competitors in financial performance $(2011 ; 2012)$ and customer satisfaction (2012). Ellinger and colleagues examined compared ranked and non-ranked firms (a relation).

Second, this study aimed to draw attention to asymmetric benefits that some firms may be receiving because they operate in industries where integrative and collaborative supply chain 
management practices may be most effective. To do so, this study discussed the supported market valuation effects in light of: (1) the influence and potential limitations of the integrative and collaborative approach to supply chain management, and (2) the gap in our understanding of how supply chain management contributes to firm performance under different competitive conditions. In doing so the study adds to a body of literature that supports alternative theory development in strategic supply chain management research (e.g. Burgess et al., 2006; Carter, 2011; Fabbe-Costes \& Jahre, 2008).

The empirical portion of this study shows the market valuation benefit afforded to firms recognized for supply chain management competence is large and may create some potential liability for firms that later lose this recognition. In addition, the above discussion on the current limitations in supply chain research suggests the integrative and collaborative supply chain management approach that heavily influences current perception of supply chain competence may have bounds to its application. Thus, while this study shows firms ranked for supply chain management competence receive market valuation benefits, firms should consider the environmental context in which they are operating and their strategic priorities before concluding they will receive benefits from adopting, and then promoting their adoption, of the integrative and collaborative approach to supply chain management. Assuming the universal applicability of integrative and collaborative SCM may actually be "putting the cart before the horse".

This research may encourage some firms to strategically pursue recognition for supply chain management competence. It may also encourage firms that are already ranked for supply chain competence to maintain their standing on the ranking due to potential liability they may incur if dropped. In both situations it may be wise for firms to understand and monitor the methodology of existing rankings for supply chain competence. What are the evaluation criteria? How does my firm compare against these criteria? What are my firm's supply chain management strengths and which areas require improvement? Firms motivated to invest in integrative and collaborative supply chain management have resources at their disposal to better understand what investors and ranking organizations may expect to see as evidence of supply chain management competence. Comprehensive explanations of the underlying processes and strategic logic behind various models of integrative and collaborative supply chain management are available in research (e.g., Min et al., 2005; Min et al., 2007) as is training from not-for-profit professional associations such as the Council for Supply Chain Management Professionals (www.cscmp.org) and the Supply Chain Council (www.supplychain.org). It may also be wise, given the potential benefits of being recognized for supply chain competence, for firms to promote their supply chain management activities and strengths.

\section{References}

Allred, Chad R, Fawcett, Stanley E, Wallin, Cynthia, \& Magnan, Gregory M. (2011). A dynamic collaboration capability as a source of competitive advantage. Decision Sciences, 42(1), 129-161.

Barney, Jay B. (1992). Integrating organizational behavior and strategy formulation research: A resource based analysis. Advances in strategic management, 8(1), 39-61.

Barney, Jay, \& Felin, Teppo. (2013). what are microfoundations? The Academy of Management Perspectives, 27(2), 138-155.

Barreto, Ilídio. (2010). Dynamic capabilities: A review of past research and an agenda for the future. Journal of Management, 36(1), 256-280.

Beske, Philip, Land, Anna, \& Seuring, Stefan. (2014). Sustainable supply chain management practices and dynamic capabilities in the food industry: A critical analysis of the literature. International Journal of Production

Economics, 152, 131-143. 
Naeem, H. M., \& Hussain, N. M. (2015). Strategic Management and Supply chain Management in Organizationla Theory Persepective: A Synergistic Approach. Archives of Business Research, 3(5), 25-33.

Camuffo, Arnaldo, Furlan, Andrea, \& Rettore, Enrico. (2007). Risk sharing in supplier relations: an agency model for the Italian air-conditioning industry. Strategic Management Journal, 28(12), 1257-1266.

Carter, Craig R. (2011). A call for theory: the maturation of the supply chain management discipline. Journal of Supply Chain Management, 47(2), 3-7.

Carter, Craig R, \& Rogers, Dale S. (2008). A framework of sustainable supply chain management: moving toward new theory. International journal of physical distribution \& logistics management, 38(5), 360-387.

Chen, Haozhe, Daugherty, Patricia J, \& Landry, Timothy D. (2009). Supply chain process integration: a theoretical framework. Journal of Business Logistics, 30(2), 27-46.

Cheng, Liang-Chieh Victor, \& Grimm, Curtis M. (2006). The application of empirical strategic management research to supply chain management. Journal of Business Logistics, 27(1), 1-55.

Christmann, Petra. (2000). Effects of "best practices" of environmental management on cost advantage: The role of complementary assets. Academy of Management journal, 43(4), 663-680.

Christmann, Petra. (2004). Multinational companies and the natural environment: Determinants of global environmental policy. Academy of Management Journal, 47(5), 747-760.

Christopher, Martin, Peck, Helen, \& Towill, Denis. (2006). A taxonomy for selecting global supply chain strategies. The International Journal of Logistics Management, 17(2), 277-287.

Christopher, Martin, \& Towill, Denis R. (2002). Developing market specific supply chain strategies. The International Journal of Logistics Management, 13(1), 1-14.

Co-Editors: Benn Lawson, Paul D Cousins, Squire, Brian, Burgess, Kevin, Singh, Prakash J, \& Koroglu, Rana. (2006). Supply chain management: a structured literature review and implications for future research. International Journal of Operations \& Production Management, 26(7), 703-729.

D'Aveni, Richard A, Dagnino, Giovanni Battista, \& Smith, Ken G. (2010). The age of temporary advantage. Strategic Management Journal, 31(13), 1371-1385.

D’Aveni, Richard A, \& Gunther, Robert. (2007). Hypercompetition. Managing the dynamics of strategic maneuvering Das Summa Summarum des Management (pp. 83-93): Springer.

Delmas, Magali, Hoffmann, Volker H, \& Kuss, Matthias. (2011). under the tip of the iceberg: Absorptive capacity, environmental strategy, and competitive advantage. Business \& Society, 50(1), 116-154.

Dyer, Jeffrey H, \& Singh, Harbir. (1998). the relational view: Cooperative strategy and sources of interorganizational competitive advantage. Academy of management review, 23(4), 660-679.

Elsenhardt, Kathleen M, \& Martin, Jeffrey A. (2000). Dynamic capabilities: What are they? Strategic management journal, 21(1), 1105-1121.

Fawcett, Stanley E, Ellram, Lisa M, \& Ogden, Jeffrey A. (2014). Supply chain management: from vision to implementation: Pearson.

Fawcett, Stanley E, Wallin, Cynthia, Allred, Chad, Fawcett, Amydee M, \& Magnan, Gregory M. (2011). Information technology as an enabler of supply chain collaboration: a dynamic-capabilities perspective. Journal of Supply Chain Management, 47(1), 38-59.

Fraj, Elena, Martínez, Eva, \& Matute, Jorge. (2013). Green marketing in B2B organisations: an empirical analysis from the natural-resource-based view of the firm. Journal of Business \& Industrial Marketing, 28(5), 396-410.

Gersick, Connie JG. (1991). Revolutionary change theories: A multilevel exploration of the punctuated equilibrium paradigm. Academy of management review, 16(1), 10-36.

Hart, Stuart L, \& Dowell, Glen. (2010). a natural-resource-based view of the firm: Fifteen years after. Journal of Management, 0149206310390219.

Hart, Stuart L, \& Dowell, Glen. (2011). Invited editorial: A natural-resource-based view of the firm fifteen years after. Journal of Management, 37(5), 1464-1479.

Hendricks, Kevin B, \& Singhal, Vinod R. (2003). The effect of supply chain glitches on shareholder wealth. Journal of Operations Management, 21(5), 501-522. 
Hendricks, Kevin B, Singhal, Vinod R, \& Zhang, Rongrong. (2009). the effect of operational slack, diversification, and vertical relatedness on the stock market reaction to supply chain disruptions. Journal of Operations Management, 27(3), 233-246.

Hillman, Amy J, \& Keim, Gerald D. (2001). Shareholder value, stakeholder management, and social issues: what's the bottom line? Strategic management journal, 22(2), 125-139.

Ishaq, Muhammad Ishtiaq, Hussain, Nazia, Khaliq, Waseem, \& Waqas, Muhammad. A Review on Triple-A Supply Chain Performance.

Ketchen, David J, \& Giunipero, Larry C. (2004). The intersection of strategic management and supply chain management. Industrial Marketing Management, 33(1), 51-56.

Ketchen, David J, Hult, G Tomas M, \& Slater, Stanley F. (2007). Toward greater understanding of market orientation and the resource-based view. Strategic Management Journal, 28(9), 961-964.

Lee, Hau L. (2004). The triple-A supply chain. Harvard business review, 82(10), 102-113.

Lee, Jae-Nam, Miranda, Shaila M, \& Kim, Yong-Mi. (2004). IT outsourcing strategies: Universalistic, contingency, and configurational explanations of success. Information Systems Research, 15(2), 110-131.

Menguc, Bulent, \& Ozanne, Lucie K. (2005). Challenges of the "green imperative": a natural resource-based approach to the environmental orientation-business performance relationship. Journal of Business Research, 58(4), 430-438.

Miles, Raymond E, \& Snow, Charles C. (2007). Organization theory and supply chain management: An evolving research perspective. Journal of Operations Management, 25(2), 459-463.

Min, Soonhong, Mentzer, John T, \& Ladd, Robert T. (2007). A market orientation in supply chain management. Journal of the Academy of Marketing Science, 35(4), 507-522.

Min, Soonhong, Roath, Anthony S, Daugherty, Patricia J, Genchev, Stefan E, Chen, Haozhe, Arndt, Aaron D, \& Glenn Richey, R. (2005). Supply chain collaboration: what's happening? The international journal of logistics management, 16(2), 237-256.

Pacheco-de-Almeida, Gonçalo. (2010). Erosion, time compression, and self-displacement of leaders in hypercompetitive environments. Strategic Management Journal, 31(13), 1498-1526.

Peteraf, Margaret, Di Stefano, Giada, \& Verona, Gianmario. (2013). the elephant in the room of dynamic capabilities: Bringing two diverging conversations together. Strategic Management Journal, 34(12), 1389-1410.

Porter, Michael E, \& Millar, Victor E. (1985). How information gives you competitive advantage: Harvard Business Review, Reprint Service.

Rajaguru, Rajesh, \& Matanda, Margaret Jekanyika. (2013). Effects of inter-organizational compatibility on supply chain capabilities: Exploring the mediating role of inter-organizational information systems (IOIS) integration. Industrial Marketing Management, 42(4), 620-632.

Saeed, Khawaja A, Malhotra, Manoj K, \& Grover, Varun. (2011). Interorganizational System Characteristics and Supply Chain Integration: An Empirical Assessment*. Decision Sciences, 42(1), 7-42.

Teece, David J. (2007). Explicating dynamic capabilities: the nature and microfoundations of (sustainable) enterprise performance. Strategic management journal, 28(13), 1319-1350.

Teece, David J, Pisano, Gary, \& Shuen, Amy. (1997). Dynamic capabilities and strategic management.

Waller-one of the usual editors, Matthew, Fabbe-Costes, Nathalie, \& Jahre, Marianne. (2008). Supply chain integration and performance: a review of the evidence. The International Journal of Logistics Management, 19(2), 130-154.

Wernerfelt, Birger. (1984). A resource-based view of the firm. Strategic management journal, 5(2), 171-180.

Williamson, Oliver E. (2008). Outsourcing: Transaction cost economics and supply chain management*. Journal of supply chain management, 44(2), 5-16.

Wisner, Joel, Tan, Keah-Choon, \& Leong, G. (2015). Principles of supply chain management: a balanced approach: Cengage Learning. 
Naeem, H. M., \& Hussain, N. M. (2015). Strategic Management and Supply chain Management in Organizationla Theory Persepective: A Synergistic Approach. Archives of Business Research, 3(5), 25-33.

Xie, Charlene, Anumba, Chimay J, Lee, Tzong-Ru, Ho, William, Dey, Prasanta K, \& Lockström, Martin. (2011). Strategic sourcing: a combined QFD and AHP approach in manufacturing. Supply Chain Management: An International Journal, 16(6), 446-461.

Zahra, Shaker A, Sapienza, Harry J, \& Davidsson, Per. (2006). Entrepreneurship and dynamic capabilities: a review, model and research agenda*. Journal of Management studies, 43(4), 917-955 